\title{
Using a tracer technique to identify the extent of non-ideal flows in the continuous mixing of non-Newtonian fluids
}

\author{
D. Patel, F. Ein-Mozaffari and M. Mehrvar \\ Department of Chemical Engineering, Ryerson University, Toronto, Ontario, Canada
}

\begin{abstract}
The identification of non-ideal flows in a continuous-flow mixing of non-Newtonian fluids is a challenging task for various chemical industries: plastic manufacturing, water and wastewater treatment, and pulp and paper manufacturing. Nonideal flows such as channelling, recirculation, and dead zones significantly affect the performance of continuous-flow mixing systems. Therefore, the main objective of this paper was to develop an identification protocol to measure non-ideal flows in the continuous-flow mixing system. The extent of non-ideal flows was quantified using a dynamic model that incorporated channelling, recirculation, and dead volume in the mixing vessel. To estimate the dynamic model parameters, the system was excited using a frequency-modulated random binary input by injecting the saline solution (as a tracer) into the fresh feed stream prior to being pumped into the mixing vessel. The injection of the tracer was controlled by a computer-controlled on-off solenoid valve. Using the trace technique, the extent of channelling and the effective mixed volume were successfully determined and used as mixing quality criteria. Such identification procedures can be applied at various areas of chemical engineering in order to improve the mixing quality.
\end{abstract}

\section{INTRODUCTION}

Effective mixing is vital to successful process results for many industries such as biotechnology, petrochemical, food, polymer processing, pulp and paper, drinking water and wastewater treatment, agrichemicals, and pharmaceuticals [1]. The continuous-flow mixing has many advantages over batch mixing operations such as it provides high production rates, improves process control, and saves operation time and labor cost by eliminating loading and unloading materials and between-cycle cleaning [2]. Continuous-flow mixing in stirred vessels is frequently used in blending with chemical reaction, gas absorption, extraction, dissolution, crystallization, and polymerization [3]. As a consequence of the complex rheology of non-Newtonian fluids, the study of continuous-flow mixing of such fluids is more complicated than that of Newtonian fluids [4]. Non-Newtonian fluids with yield stress comprise pulp suspension, food substances such as ketchup and mayonnaise, paint, cement, pigment slurries, certain polymer and biopolymer solutions, and wastewater sludge [5]. The complex rheology of such fluids can create substantial deviation from ideal mixing $[6,7]$. The previous studies identified non-ideal flows (channeling: a portion of the feed directly flows to the exit without entering the mixing zone; recirculation: a portion of the fluid recirculates within a mixing zone; dead zones: fluid is stagnant or flows much more slowly than the bulk of the fluid) in continuousflow mixing systems. These non-ideal flows should be avoided as they decrease the efficiency of the mixing system. Although several studies have been done on the continuous-flow mixing of Newtonian fluids [8-11]; there is little information available in the literature on the continuous-flow mixing of non-Newtonian fluids. Thus, it is imperative to study the dynamic behavior of continuous-flow mixing under realistic mixing conditions since ignoring non-ideal flows can lead to errors in the system design [12]. There are various factors affecting the continuous-flow mixing which include fluid rheology, fluid flow rate, fluid depth in the vessel, position of the inlet and the outlet of the vessel, number of inlets, vessel diameter, vessel bottom head geometry (flat, dished or cone-shaped), number of baffles and their geometry, type of impeller, impeller diameter, impeller geometry, impeller speed, impeller off-bottom clearance, and impeller pumping direction.

It is clear based on the literature review that there is a need to develop a practical methodology that enables us to identify non-ideal flows in the continuous-flow mixing of non-Newtonian fluids. To achieve these objectives, we designed, fabricated and installed an experimental setup in order to investigate the dynamic behavior of continuousflow mixing of pseudoplastic fluids possessing yield stress. The detailed experimental procedure was developed to identify non-ideal flows such as channeling, recirculation, and dead volume. Dynamic tests were carried out using the frequency-modulated random binary input of a brine solution (a tracer) with the feed. A dynamic model that incorporated non-ideal flows within the mixing vessel was validated and used in this study.

\section{EXPERIMENTAL SETUP AND PROCEDURE}

To analyze the dynamic behavior of a continuous-flow mixing system, the experimental setup shown in Figure 1 was utilized in this study. A transparent flat-bottomed cylindrical tank with a diameter $(T)$ of $0.38 \mathrm{~m}$ and a height of $0.60 \mathrm{~m}$ was used as a mixing vessel. A tank was fitted with four equally spaced baffles $(0.04 \mathrm{~m}$ wide, $0.012 \mathrm{~m}$ thick and length equal to the tank height) to the vessel wall to avoid vortex. The inlet and outlet were located at the top $\left(r=0.13 \mathrm{~m}, \theta=90^{\circ}\right.$, and $\left.z=0.38 \mathrm{~m}\right)$ and bottom $\left(r=0.13 \mathrm{~m}, \theta=315^{\circ}\right.$, and $\left.z=0.00 \mathrm{~m}\right)$ of the mixing vessel, respectively. The diameter of the inlet and outlet 


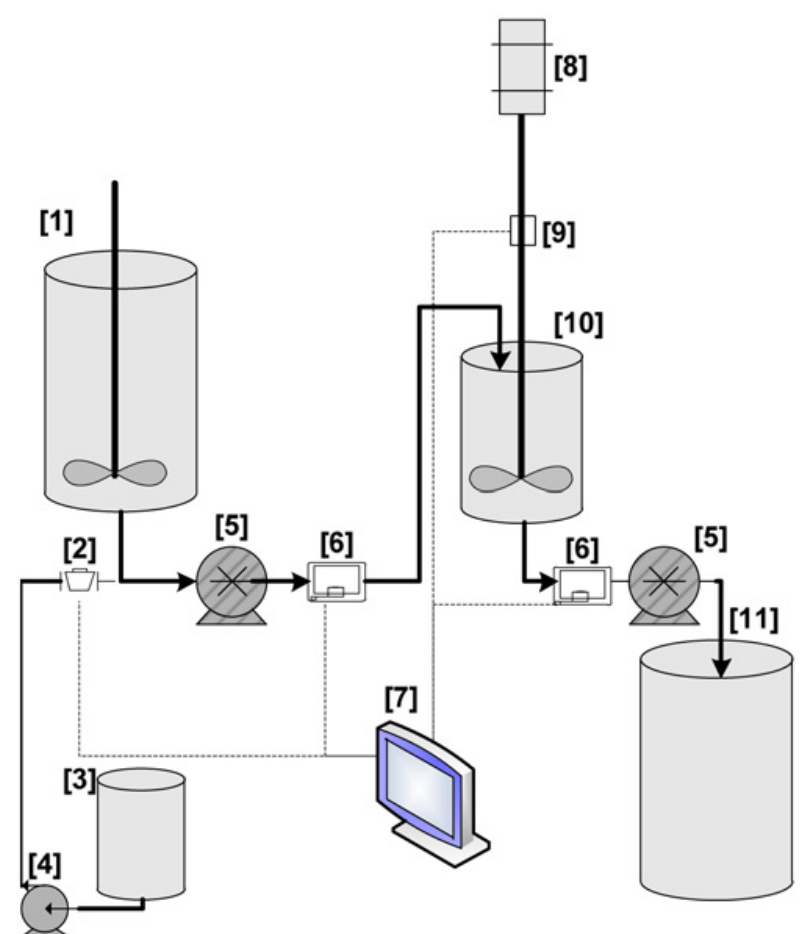

Figure 1. Experimental setup: [1] feed tank, [2] solenoid valve, [3] tracer tank, [4] metering pump, [5] progressing cavity pump, [6] conductivity sensor, [7] data acquisition system, [8] electric motor, [9] torque meter, [10] mixing tank, and [11] discharge tank.

pipes was $0.025 \mathrm{~m}$. The mixing tank was equipped with a top-entering impeller driven by a 2-hp motor. The impeller speed was set to the desired number of revolution per minute (rpm) using a variable frequency drive (VFD). The impeller torque and speed were measured using a rotary torque transducer (Staiger Mohilo, Lorch, Germany) and a tachometer, respectively. Two flexible couplings were installed on both sides of the torque transducer to accommodate radial, angular, and axial misalignments that accompany shaft rotation.

To perform the experiments, the fluid was pumped from the feed tank $\left(0.30 \mathrm{~m}^{3}\right.$ cylindrical tank) to the mixing vessel using a progressive cavity pump (Moyno Industrial Products, Springfield, OH, USA). The solution was agitated in the mixing vessel and finally was collected in the discharge tank $\left(0.30 \mathrm{~m}^{3}\right.$ cylindrical tank) using a progressive cavity discharge pump (Moyno Industrial Products, Springfield, OH, USA). Both feed and discharge pumps were equipped with a variable frequency drive to control the operations and to maintain a constant liquid flow rate through the mixing tank. To maintain the fluid height at the desired level in the mixing tank, the inlet flow rate was kept constant and the outlet flow rate was manipulated. Dynamic tests were performed by exciting the system and observing the input and the output conductivities over a specified time interval. The system was excited by injecting a saline solution $(\mathrm{NaCl}$ solution as a tracer) into the fresh feed stream prior to being pumped into the mixing vessel using a metering pump (Milton Roy, USA). The injection of the tracer was controlled by a computer-controlled on-off solenoid valve (Ascolectric Ltd., Canada). The conductivity values of the input and output streams as a function of time were measured using flow-through conductivity sensors (RoseMount Analytical, Irvine, CA, USA). The data were recorded using a data acquisition system controlled by LABVIEW software (National Instruments, Austin, TX, USA) to estimate dynamic model parameters.

The non-Newtonian fluid used in this study was xanthan gum solution in water. Xanthan gum is a high molecular weight microbial exopolypolysaccharide polymer produced by a fermentation process with the bacterium Xanthomonas campestris [13]. Xanthan gum solution is a pseudoplastic fluid with yield stress and its rheology can be described by the Herschel-Bulkley model $[14,15]$ :

$$
\tau=\tau_{y}+K(\dot{\gamma})^{n}
$$

where $\tau$ is the shear stress, $\tau_{y}$ is the yield stress, $K$ is the consistency index, $\dot{\gamma}$ is the shear rate and $n$ is the power-law index. The average shear rate can be used to evaluate the apparent viscosity $(\eta)$ of the Herschel-Bulkley fluid [14]:

$$
\eta=\frac{\tau}{\dot{\gamma}_{\text {avg }}}=\frac{\tau_{y}+K(\dot{\gamma})^{n}}{\dot{\gamma}_{\text {avg }}}
$$

According to the Metzner and Otto [16] classical equation, the average shear rate $\left(\dot{\gamma}_{\text {avg }}\right)$ close to the impeller in the mixing vessel is directly proportional to the rotational speed of the impeller $(N)$ :

$$
\dot{\gamma}_{\text {avg }}=k_{S} N
$$

where $k_{S}$ is a function of the impeller type. The rheological parameters of xanthan gum solutions have been reported by Saeed and Ein-Mozaffari [17]. In this study, the effect of impeller speed and the impeller types on the extent of the non-ideal flows in a continuous-flow mixing system were explored using the dynamic tests.

\section{DYNAMIC MODEL}

The dynamic model developed by Ein-Mozaffari [18] for the continuous-flow mixing was used in this study to quantify the extent of the non-ideal flows such as channeling, recirculation, and dead volume. This model allows for two parallel flow paths through the mixing vessel: (i) the channeling zone comprising the first-order transfer function with a time delay, and (ii) the mixing zone comprising the first order transfer function with a time delay and the feedback for recirculation. The combined transfer function for the above system in a continuoustime domain can be expressed mathematically as follows $[7,19,20]$ :

$$
G=\frac{f e^{-T_{1} s}}{1+\tau_{1} s}+\frac{(1-f)(1-R) \frac{e^{-T_{2} s}}{1+\tau_{2} s}}{1-\frac{(R) e^{T_{2} s}}{1+\tau_{2} s}}
$$

where $G$ is the transfer function of the vessel, $f$ represents the portion of the fluid that is channeled in the mixing tank and $1-f$ is the fraction of the fluid that enters the mixing zone. A portion of the fluid, $R$, exiting the mixing zone 
can be recirculated within the mixing zone. Parameters $\tau_{1}$ and $\tau_{2}$ are the time constants for the channeling and mixing zones, respectively. Parameters $T_{1}$ and $T_{2}$ are the time delays for the channeling and mixing zones, respectively. To estimate the non-ideal parameters such as channeling, recirculation, and dead zones, the mixing vessel was excited by an input signal in order to observe the system response (output signal). By measuring the input and output responses of the mixing vessel, the dynamic model parameters were estimated using the numerical method developed by Kammer et al. [21]. Since data were measured at a fixed time interval (in this study the sampling time was $1 \mathrm{~s}$ ), the continuous-time model (Eq. (4)) was transformed into a simple discrete-time model (Eq. (5)) using a zero-order hold [22]. The discrete-time domain transfer function $\hat{G}(q)$ equivalent to Equation (4) is given as follows [21]:

$$
\begin{aligned}
& \hat{G}(q)= \\
& \frac{\alpha_{1} q^{-d_{1}}+\alpha_{2} q^{-\left(d_{1}+1\right)}+\alpha_{3} q^{-d_{2}}+\alpha_{4} q^{-\left(d_{2}+1\right)}+\alpha_{5} q^{-\left(d_{1}+d_{2}\right)}}{1+\alpha_{6} q^{-1}+\alpha_{7} q^{-2}+\alpha_{8} q^{-d_{2}}+\alpha_{9} q^{-\left(d_{2}+1\right)}}
\end{aligned}
$$

$$
\begin{array}{ll}
\text { where } \alpha_{1}=f\left(1-a_{1}\right), & \alpha_{7}=a_{1} a_{2}, \\
\alpha_{2}=-f\left(1-a_{1}\right) a_{2}, & \alpha_{8}=-R\left(1-a_{2}\right), \\
\alpha_{3}=(1-f)(1-R)\left(1-a_{2}\right), & \alpha_{9}=R a_{1}\left(1-a_{2}\right), \\
\alpha_{4}=-(1-f)(1-R) a_{1}\left(1-a_{2}\right), & a_{i}=e^{-t_{s} / \tau_{i}}, i=1,2, \\
\alpha_{5}=-f R\left(1-a_{1}\right)\left(1-a_{2}\right), & d_{i}=1+\frac{T_{i}}{t_{s}}, i=1,2, \\
\alpha_{6}=-a_{1}-a_{2}, d_{2} \geq d_{1}, &
\end{array}
$$

where $T_{i}, t_{s}$ and $q^{-1}$ are the $\mathrm{i}^{\text {th }}$ time delay, sampling time, and backward shift operator, respectively. The backward shift operator is defined as $q^{-1} f(K)=f(K-1)$. The model parameters $\left(f, R, a_{1}, a_{2}, d_{1}\right.$, and $\left.d_{2}\right)$ are estimated by minimizing the cost function $\left(J_{\xi}\right)$ as follows:

$$
J_{\xi}=\frac{1}{\xi} \sum_{t=1}^{\xi}\left[y_{t}^{b}-\hat{G}(q) u_{t}^{b}\right]^{2}
$$

where $\xi, y_{t}^{b}$, and $u_{t}^{b}$ are the length of the data set, measured output, and measured input, respectively. Two distinct stages were used during the minimum search process: an efficient but less accurate least squares minimization for the optimal delays, followed by an accurate gradient search for all parameters using a sequential quadratic programming (SQP) method [23,24]. This method uses an optimization technique to solve the constrained nonlinear problems. If a recirculation exists in the mixing vessel, a series of first-order exponential responses would have appeared in the dynamic responses [25]. The parameter $R$ was set to zero as the recirculation of the fluid was not observed in the dynamic responses of the laboratory-scale mixing vessel in which Equation (4) was further simplified as follows [19]:

$$
G=\frac{f e^{-T_{1} s}}{1+\tau_{1} s}+(1-f) \frac{e^{-T_{2} s}}{1+\tau_{2} s} .
$$

Two parameters were used to quantify the flow nonideality: $f$, the degree of channeling in the vessel, and $V_{\text {fullymixed }} / V$, the ratio of the fully mixed volume ( $\left.V_{\text {fully mixed }}\right)$ in the vessel to the total solution volume $(V)$ in the vessel. The fully mixed volume was given by [26]:

$$
\frac{V_{\text {fully mixed }}}{V}=\frac{Q \tau_{2}(1-f)}{V}
$$

where $Q$ is the solution flow rate through the mixing vessel.

\section{EXCITATION PROCEDURE, INPUT SIGNAL DESIGN, AND MODEL VALIDATION}

System identification is the field of modeling dynamic systems from the experimental data [27,28]. Generally, an identification experiment is performed by exciting a system using some sort of input signal such as a step, a sinusoidal or a random signal. The system identification procedure broadly includes (1) excite the system and collect input-output data, (2) choose a dynamic model structure, (3) choose a numerical criterion to estimate the unknown parameters of the dynamic model from inputoutput data, and (4) validate the model by using new inputoutput data.

First, to estimate the model parameters, the system must be excited by a proper input signal and the choice of this input signal has a very significant impact on the observed data. Actually, all modes of the system should be excited during the identification experiments [27]. For instance, one single sinusoidal signal with the frequency $\omega$ only gives information of the value of the frequency function at $\omega$. There are infinitely many systems that give the same output with this input. It is thus important that the input signal contain enough frequency. For this purpose, a frequency-modulated random binary input signal was designed in this study.

An identification experiment was performed by exciting the system and examining the input and output conductivities over a precise time interval [25]. To excite the system, the saline solution as a tracer was injected through a computer controlled solenoid valve into the feed stream to estimate the unknown parameters of the parametric model (Eq. (7)) [28]. The choice of sampling time $\left(t_{s}\right)$ was related to the time constant of the system. Sampling time that is considerably faster than the system dynamics leads to data redundancy and relatively small information value in the new data points. Sampling that is considerably slower than the system dynamics leads to serious difficulties determining the parameters that describes the system dynamics. For a process with a dominant time constant, it is recommended that the sampling time $\left(t_{s}\right)$ be chosen as about $20 \%$ of the time constant value [29]. In this study the sampling time of one second was chosen. There are several possible deficiencies in the data collected from the identification experiments such as signal level drift or high-frequency disturbances above the frequency of interest to the system dynamics, obvious outliers, missing data, and non continuous data record [30]. These types of deficiency should be removed from the collected data prior to use. Since these deficiencies were not observed in input-output data recorded during the identification experiments made 


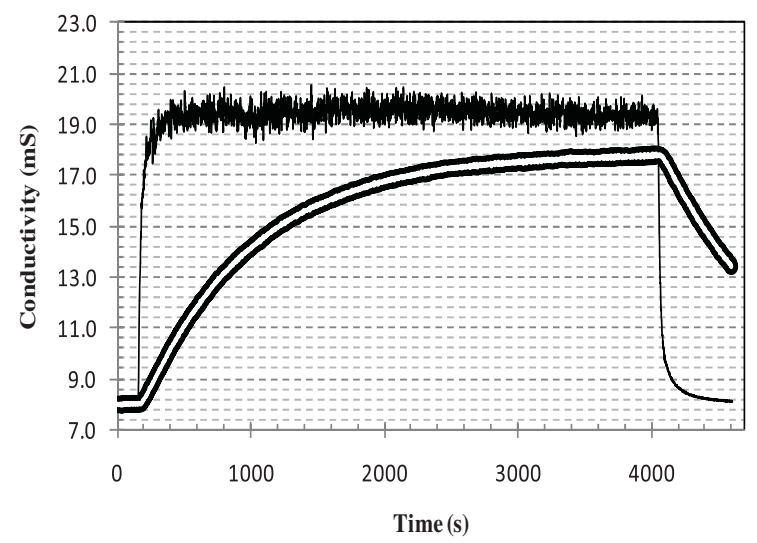

Figure 2. System excitation using a rectangular pulse: input and output signals in black lines and model output in white line. (3AH, $Q=579 \mathrm{Lh}^{-1}, 251 \mathrm{rpm}, 0.5 \%$ xanthan gum, $D=T / 2.1$, $C=H / 2.7, H=T / 0.93)$.

on the mixing vessel, the signals were not preprocessed and were used directly in the identification algorithm. As the input signal was controlled by an on-off solenoid valve, the excitation provided in the dynamic tests was restricted to the binary sequences. The process of model identification required two experiments: (1) system excitation by a rectangular pulse, and (2) system excitation by a frequency-modulated random binary signal. These experiments were then followed by model validation.

\subsection{System excitation by a rectangular pulse}

In the first experiment (Fig. 2), the input signal was a rectangular pulse to allow the estimation of an approximate model (the white line in Fig. 2) to design the excitation for the second experiment. A parametric model (Eq. (7)) of the process was fitted to the recorded input-output sequences. To estimate correctly the unknown parameters in parametric models, it is important that the input signal be persistently exciting meaning that all modes of the system should be excited during the identification experiment [28]. Thus, a simple input as shown in Figure 2 will not provide enough excitation to accurately identify the model parameters. However, transient analysis (step response) is an excellent method to get a quick and easy insight into cause and effect relationship, time delay, time constant, and static gains. This also provides an opportunity for users to visualize the system response. From the input and output conductivity data, the model parameters were calculated using a MATLAB program [18].

\subsection{System excitation by a frequency - modulated random binary signal}

In order to improve the quality of the parameter estimation, another experiment was designed. The purpose of this experimental design was to focus the excitation energy at frequencies where the Bode plot is sensitive to parameter variations [21]. For this intention, the

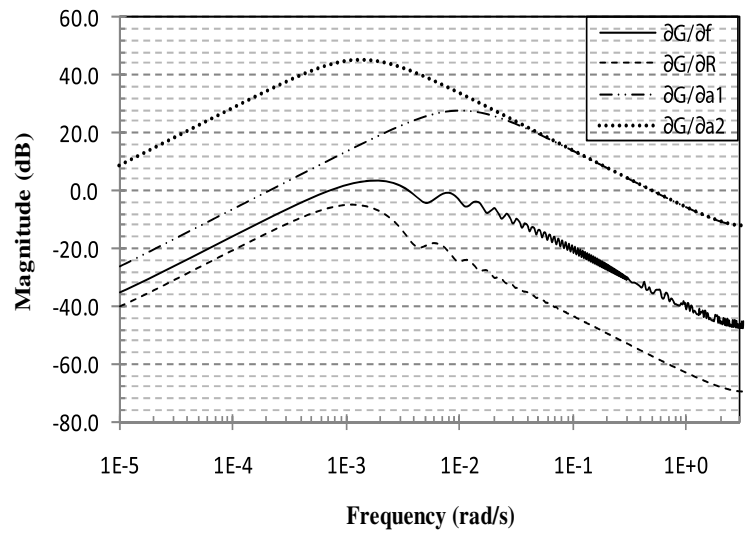

Figure 3. The magnitude of the Bode plot for the partial derivatives of the approximate model.

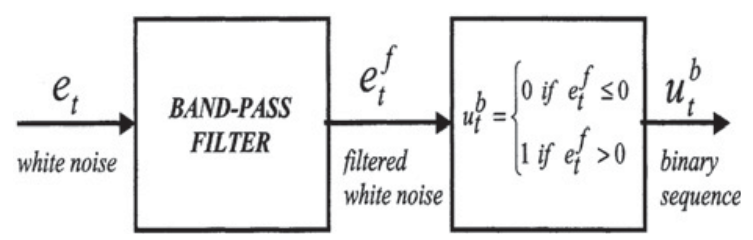

Figure 4. Procedure for designing a frequency-modulated random binary input signal.

magnitudes of the Bode plot for the partial derivatives of the approximate model (from the first excitation) with respect to model parameters $\left(f, R, a_{1}\right.$, and $\left.a_{2}\right)$ were calculated (Fig. 3). As shown in Figure 3, the frequencies at the maximum magnitudes were obtained: $\omega_{f}=2.0612 \times 10^{-3} \mathrm{rad} \mathrm{s}^{-1}, \quad \omega_{R}=1.1575 \times$ $10^{-3} \mathrm{rad} \mathrm{s}^{-1}, \omega_{a 1}=10.000 \times 10^{-3} \mathrm{rad} \mathrm{s}^{-1}$, and $\omega_{a 2}=$ $1.5446 \times 10^{-3} \mathrm{rad} \mathrm{s}^{-1}$. Hence, the excitation energy for the second experiment was concentrated at frequencies from $1.1575 \times 10^{-3} \mathrm{rad} \mathrm{s}^{-1}$ to $10.000 \times 10^{-3} \mathrm{rad} \mathrm{s}^{-1}$. By having this information it is possible to design a better signal for second excitation. The procedure for designing a frequency-modulated random binary input signal for the second experiment is shown in Figure 4 [25]. A zeromean white-noise signal $\left(e_{t}\right)$ was filtered by a band-pass filter with cut-off frequencies of $1.1575 \times 10^{-3} \mathrm{rad} \mathrm{s}^{-1}$ and $10.000 \times 10^{-3} \mathrm{rad} \mathrm{s}^{-1}$. Then, the filtered signal was converted into a binary sequence using the following function:

$$
u_{t}^{b}=\left\{\begin{array}{l}
0 \quad \text { if } e_{t}^{f} \leq 0 \\
1 \text { if } e_{t}^{f}>0
\end{array}\right.
$$

Such a conversion might change the spectrum of the signal, but it is always possible to check this spectrum before using the signal and see if it is acceptable [28]. This frequency-modulated random binary input was used to perform the second experiment, where Figure 5 shows the input and output signals in black line and the model response to the given excitation in a white line.

\subsection{Model validation}

Model validation had two steps. In the first step, the system was excited using a frequency-modulated random binary 


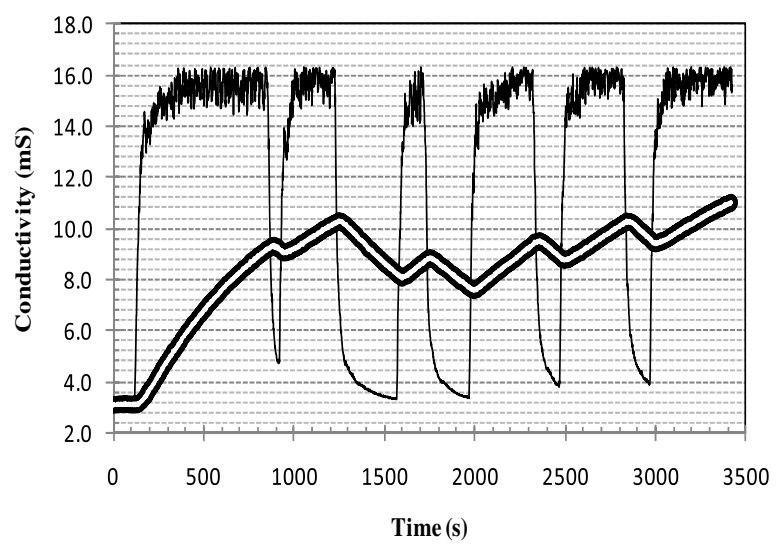

Figure 5. System excitation using a frequency-modulated random binary input signal: experimental input and output in black and model output in white. ( $3 \mathrm{AH}, Q=579 \mathrm{Lh}^{-1}, 251 \mathrm{rpm}$, $0.5 \%$ xanthan gum, $D=T / 2.1, C=H / 2.7, H=T / 0.93)$.

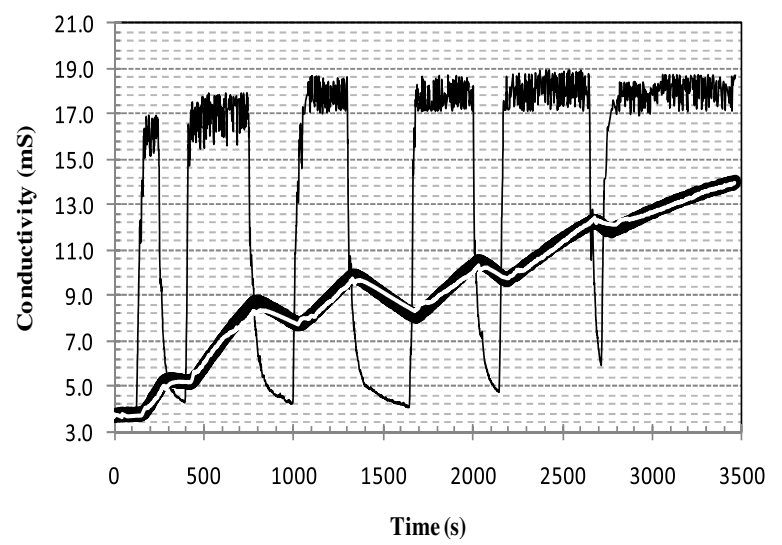

Figure 6. Model validation: new input and output signals (second set of experiment) in black and estimated model output from the first set of data in white $\left(3 \mathrm{AH}, Q=579 \mathrm{Lh}^{-1}, 251 \mathrm{rpm}, 0.5 \%\right.$ xanthan gum, $D=T / 2.1, C=H / 2.7, H=T / 0.93$ ).

input. The input and output signals were recorded and used to calculate the model parameters (Fig. 5). In the second step, the system was excited by a new input signal under the same operating conditions and the input and output data were recorded. The input signal employed in the second experiment and the model parameters estimated from the first experiment were used to calculate the output signal. These estimated output signals were then compared to the output signals recorded in the second experiment (Fig. 6). In this figure the measured output is shown by a black line and the estimated output is shown by a white line. It shows that measured output and estimated output are very close to each other.

Table 1 shows the model parameters $(f$ and $V_{\text {fullymixed }} / V$ ) obtained from both experiments. It shows that the model parameters obtained from the first input signal (Fig. 5) were in good agreement with those obtained from the new input signal (Fig. 6). This implies that the estimated parameters are unique characteristics of the system under specified operating conditions. Although the discrete-time transfer function is an approximation of the continuous-time model, it provides an accurate estimation for all parameters.
Table 1. Dynamic model parameters obtained from two different input signals.

\begin{tabular}{ccccc}
\hline \multicolumn{2}{c}{ First input signal (Fig. 5) } & & \multicolumn{2}{c}{ Second input signal (Fig. 6) } \\
\cline { 5 - 5 }$f$ & $V_{\text {fully mixed }} / V$ & & $f$ & $V_{\text {fully mixed }} / V$ \\
\hline 0.1047 & 0.8951 & 0.1051 & 0.8946 \\
\hline
\end{tabular}
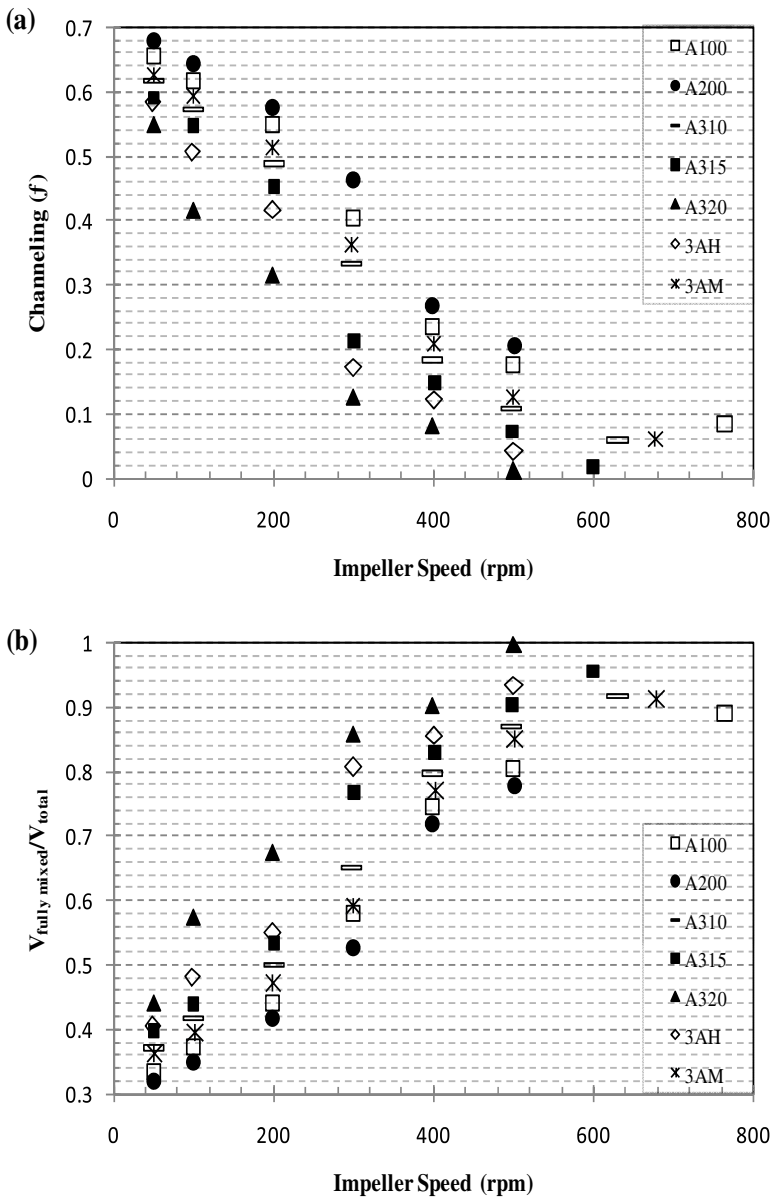

Figure 7. The effect of impeller speed and impeller type on (a) the extent of channeling and (b) the fully mixed volume ( $Q=579 \mathrm{Lh}^{-1}, 1.0 \%$ xanthan gum, $D=T / 2.1, C=H / 2.7$, $H=T / 0.93)$.

\section{RESULTS AND DISCUSSION}

Using dynamic tests, the efficiency of the continuousflow mixing of non-Newtonian fluids with yield stress in a stirred vessel in terms of reducing the non-ideal flows (channeling and dead volume) and improving the fully mixed volume was successfully measured. Figure 7 illustrates the extent of channeling and the fraction of fully mixed volume as a function of impeller speed. As expected, the channeling decreased and the fully mixed volume increased with an increase in impeller speed. At higher impeller speed, xanthan gum solution was agitated vigorously and disrupted further away from the impeller, leading to improved mixing by reducing the extent of non-ideal flows. The other researchers also observed a similar phenomenon [17]. The optimum impeller speed at which the channeling approaches zero and the fully mixed 
volume approaches the total volume of the fluid within the mixing tank should be preferred, as further increases in the impeller speed will lead to more power consumption for the same extent of the fully mixed volume.

In addition to the impeller speed, the effect of impeller type on the dynamic performance of the continuous-flow mixing was also explored. This study employed seven axial-flow impellers (Lightnin A100, A200, A310, A315, A320; HG 3AH and 3AM). The efficiency of each impeller in terms of the extent of channeling and fully mixed volume is depicted in Figure 7. The hydrofoil impellers with a high solidity ratio include A320, A315, and $3 \mathrm{AH}$ and a low solidity ratio include A310 and 3AM. The hydrofoil impellers with high solidity ratios are more effective for the mixing of the viscous fluids than those with low solidity ratios [31]. Figure 7 shows that the A320, A315, and 3AH impellers (high solidity ratio) were more effective than the A310 and 3AM impellers (low solidity ratio) in reducing the effect of channeling and dead volume in the viscous system. Results show that the A200 impeller was the least effective, while the A320 impeller was the most effective in reducing the effect of channeling and dead volume among the impellers utilized in this study. The power consumed per unit volume by the A320 impeller when the channeling approached zero and fully mixed volume approached the total fluid volume within the tank was the least power consumption among all axial-flow impellers. These results are in very good agreement with those reported in the literature [17].

\section{CONCLUSIONS}

An experimental setup was designed and fabricated to investigate the dynamic behavior of the continuous-flow mixing of a pseudoplastic fluid with yield stress (xanthan gum solution). Using a tracer technique, the existence of non-ideal flows within the mixing vessel was successfully identified. To measure the extent of non-ideal flows, a dynamic model that incorporated channeling, recirculation, and dead volume was employed in this study. Dynamic tests were carried out using a frequency-modulated random binary input of a brine solution (a tracer) with the feed to measure the extent of non-ideal flows in the mixing vessel. The variables examined included the impeller speed and impeller type. The identification technique developed in this study can be utilized to find optimal operating conditions and design parameters for the continuous-flow mixing processes.

The financial supports of the Natural Science and Engineering Research Council of Canada (NSERC) and Ontario Graduate Scholarship in Science and Technology (OGSST) are gratefully acknowledged.

\section{NOMENCLATURE}

C Impeller off-bottom clearance (m)

$D$ Impeller diameter (m)

$e_{t} \quad$ Zero-mean white-noise signal

$\begin{array}{ll}e_{t}^{f} & \text { Filtered white-noise signal } \\ f & \text { Percentage of channeling (fraction) } \\ G & \text { Transfer function } \\ H & \text { Fluid height in the vessel (m) } \\ J_{\xi} & \text { Cost function } \\ k_{S} & \text { Metzner-Otto constant (dimensionless) } \\ K & \left.\text { Consistency index (Pa } \mathrm{s}^{n}\right) \\ n & \text { Power-law index (dimensionless) } \\ N & \text { Impeller rotational speed }\left(\mathrm{s}^{-1}\right) \\ q^{-1} & \text { Backward shift operator } \\ Q & \text { Volumetric flow rate }\left(\mathrm{m}^{3} \mathrm{~s}^{-1}\right) \\ r, \theta, z & \text { Cylindrical coordinates }(\mathrm{m}, \text { deg, } \mathrm{m}) \\ R & \text { Percentage of recirculation (fraction) } \\ t_{s} & \text { Sampling time }(\mathrm{s}) \\ T & \text { Tank diameter (m) } \\ T_{1} \text { and } T_{2} & \text { Time delay (s) } \\ T_{i}, & \mathrm{i}^{\text {th }} \text { time delay (s) } \\ u_{t}^{b} & \text { Measured input }(\mathrm{mS}) \\ V \text { or } V_{\text {total }} & \text { Fluid volume inside the mixing tank }\left(\mathrm{m}^{3}\right) \\ V_{f u l l y m i x e d} & \text { Fully mixed volume }\left(\mathrm{m}^{3}\right) \\ y_{t}^{b} & \text { Measured output }(\mathrm{mS})\end{array}$

\section{Greek Letters}

$\begin{array}{ll}\dot{\gamma} & \text { Shear rate }\left(\mathrm{s}^{-1}\right) \\ \dot{\gamma}_{\text {avg }} & \text { Average shear rate }\left(\mathrm{s}^{-1}\right) \\ \xi & \text { Length of data set } \\ \eta & \text { Apparent viscosity }(\mathrm{Pa} \mathrm{s}) \\ \tau & \text { Shear stress }(\mathrm{Pa}) \\ \tau_{1} \text { and } \tau_{2} & \text { Time constant }(\mathrm{s}) \\ \tau_{y} & \text { Fluid yield stress }(\mathrm{Pa}) \\ \omega & \text { Frequency }\left(\mathrm{rad} \mathrm{s}^{-1}\right)\end{array}$

\section{Abbreviations}

HG Hayward Gordon

rpm Revolution per minute

VFD Variable frequency drive

\section{References}

[1] J.Y. Oldshue, Fluid mixing technology (McGrawHill, New York, 1983)

[2] E.B. Nauman, Chemical reactor design, optimization and scale-up (McGraw-Hill, New York, 2002)

[3] R.J. McDonough, Mixing for the Process Industries (Van Nostrand Reinhold, New York, 1992)

[4] Y.S. Sue, F.A. Holland, Chem. Process. Eng. 63, 110 (1968)

[5] A.W. Etchells, W.N. Ford, D.G.R. Short, Inst. Chem. Eng. Prog. Symp. Ser. 108, 1 (1987)

[6] F. Ein-Mozaffari, G.A. Dumont, C.P.J. Bennington, Appita J. 56 (2), 127 (2003a)

[7] F. Ein-Mozaffari, C.P.J. Bennington, G.A. Dumont, Chem. Eng. Sci. 60, 2399 (2005)

[8] P. Mavros, C. Xuereb, I. Fort, J. Bertrand, Can. J. Chem. Eng. 80, 591 (2002)

[9] K. Samaras, P. Mavros, D. Zamboulis, Ind. Eng. Chem. Res. 45, 4805 (2006) 
[10] A.R. Khopkar, P. Mavros, V.V. Ranade, J. Bertrand, Chem. Eng. Res Des. 82 (A6), 737 (2004)

[11] J. Aubin, S.M. Kresta, J. Bertrand, C. Xuereb, D.F. Fletcher, Chem. Eng. Res. Des. 84(A7), 569 (2006)

[12] O. Levenspiel, Chemical reaction engineering (John Wiley \& Sons, USA, 1998)

[13] J.F. Kennedy, I.J. Bradshaw, Prog. Ind. Microbiol. 19, 319 (1984)

[14] W.E. Herschel, R. Bulkley, Proc. Am. Soc. Test. Mat. 26 (2), 621 (1926)

[15] C.W. Macosko, Rheology: Principles, measurements, and applications (Wiley-VCH, New York, 1994)

[16] A.B. Metzner, R.E. Otto, AIChE J. 3(1), 3 (1957)

[17] S. Saeed, F. Ein-Mozaffari, J. Chem. Technol. Biotechnol. 83, 559 (2008)

[18] F. Ein-Mozaffari, Macorscale mixing and dynamic behavior of agitated pulp stock chests, PhD Thesis (University of British Columbia, BC, Canada, 2002)

[19] F. Ein-Mozaffari, L.C. Kammer, G.A. Dumont, C.P.J. Bennington, Can. J. Chem. Eng. 82, 154 (2004a)

[20] F. Ein-Mozaffari, C.P.J. Bennington, G.A. Dumont, TAPPI J. 6(2), 24 (2007)

[21] L.C. Kammer, F. Ein-Mozaffari, G.A. Dumont, C.P.J. Bennington, J. Process Control. 15, 31 (2005)
[22] D.E. Seborg, T.F. Edgar, D.A. Mellichamp, Process dynamics and control (Wiley, New York, 1989)

[23] R. Fletcher, Practical methods of optimization (John Wiley Sons, Chichester, UK, 1987)

[24] T.F. Edgar, D.M. Himmelblau, L.S. Lasdon, Optimization of Chemical Processes (McGraw-Hill, New York, 2001)

[25] F. Ein-Mozaffari, L.C. Kammer, G.A. Dumont, C.P.J. Bennington, TAPPI J. 2, 13 (2003b)

[26] F. Ein-Mozaffari, C.P.J. Bennington, G.A. Dumont, J. Pulp Paper Can. 105(5), 41 (2004b)

[27] T. Soderstrom, P. Stoica, System identification (Prentice Hall, 1989)

[28] L. Ljung, System identification: Theory for the user (PTR Prentice Hall, USA, 1999)

[29] B.A. Ogunnaike, W.H. Ray, Process dynamics, modeling and control (Oxford university press, New York, 1994)

[30] L. Ljung, T. Glad, Modeling of dynamic systems (Prentice Hall, Englewood Cliffs, NJ, 1994)

[31] E.L. Paul, V.A. Atiemo-Obeng, S.M. Kresta, Handbook of industrial mixing: Science and practice (Wiley-Interscience, 2004) 